\title{
Spawanie blach ze stopu magnezu AZ31 metodą MIG w odmianie CMT
}

\author{
Welding of AZ31 magnesium alloy by the CMT \\ variant of MIG method
}

\section{Streszczenie}

W artykule omówiono technologiczne aspekty spawania blach ze stopu magnezu niskoenergetyczną metodą CMT. Badano złącza doczołowe blach o grubości $2 \mathrm{~mm}$ wykonanych ze stopu magnezu AZ31 z wykorzystaniem drutu elektrodowego o średnicy 1,2 mm, wytworzonego z tego samego materiału (stopu AZ31). Próby prowadzono na stanowisku zrobotyzowanym z zapewnieniem wysokiej powtarzalności procesu, przy różnych parametrach, w tym z wykorzystaniem specjalnych funkcji wspomagających zajarzenie i wstępną fazę spawania. Jakość złączy oceniano na podstawie badań wizualnych i mikroskopowych.

Słowa kluczowe: CMT, stop AZ31, spawanie zrobotyzowane

\section{Abstract}

The technological aspects of welding of magnesium alloy by low energy CMT method is discussed. Butt joints of thickness $2 \mathrm{~mm}$ made of magnesium alloy AZ31 were tested using the wire electrode of $1.2 \mathrm{~mm}$ diameter, made from the same material (alloy AZ31). Tests were carried out with the use of a robotic installation that assured a high repeatability of the process and the various parameters, including the use of special features enabling ignition and initial phase of welding. The quality of joints was evaluated on the basis of visual and microscopic inspection.

Keywords: CMT, AZ 31 alloy, robot welding

\section{Wstęp}

Jako najlżejszy metaliczny materiały konstrukcyjny stopy na bazie magnezu, miały do niedawna ograniczone zastosowanie w przemyśle transportowym. Ograniczenia te wynikały głównie z uwagi na niskie, niezadowalające wskaźniki wytrzymałościowe i stosunkowo niską odporność korozyjną. Wprowadzenie pierwiastków stopowych takich jak Al, Cu, Zn, Mn i pierwiastki ziem rzadkich znacznie poprawiło zarówno właściwości mechaniczne jak i chemiczne uzyskanych stopów w porównaniu z czystym magnezem. Ciągłe modyfikacje składu chemicznego pozwoliło także na uzyskanie stopów magnezu do przeróbki plastycznej co w konsekwencji zaowocowało pojawieniem się na rynku blach wykonanych ze stopów magnezu (głównie stop AZ31).

Odrębnym zagadnieniem dotyczącym elementów ze stopów magnezu jest ich przetwarzanie, w tym kształtowanie i łączenie. Stosowanie tradycyjnych metod spawania nie pozwalały uzyskać zadowalającej jakości złączy [6] W początkowej fazie rozwoju technik łączenia magnezu próbowano wykorzystywać tradycyjne metody spajania, jednak ze względu na wysokie wymagania jakościowe i wydajnościowe, zaczęto wdrażać metody nowoczesne, np. spawanie laserowe izgrzewanie tarcioweFSW [7:9]. Główną wadą tych procesów jest ograniczona możliwość łączenia z zastosowaniem materiału dodatkowego, co w zastosowaniach przemysłowych znacznie wydłuża czas procesu (precyzyjne pozycjonowanie) i podwyższa koszty (bardzo dokładna obróbka łączonych krawędzi). Dlatego obecnie prowadzone są badania nad wysokowydajnymi technikami łączenia stopów magnezu, umożliwiającymi zmniejszanie kosztów produkcji, przy jednoczesnym skróceniu czasu procesu [4].

\section{Program i zakres badań}

Spoiny o długości ok. 70 mm układano na metalicznie czystych próbkach ze stopu magnezu AZ31 o składzie chemicznym zamieszczonym w tablicy l, o wymiarach $100 \times 50 \mathrm{~mm}$ i grubości $2 \mathrm{~mm}$. Spawano blachy nieukosowane w pozycji podolnej (spoiny czołowe bez oraz z odstępem w zakresie 0,5 $\div 1,0 \mathrm{~mm}$ ). Od strony grani zastosowano podkładkę miedzianą z rowkiem formującym (bez nadmuchu gazu osłonowego).

W oparciu o wcześniejsze doświadczenia (próby napawania) do badań wytypowano metodę MIG w odmianie niskoenergetycznej CMT (ang. Cold Metal Transfer). Zastosowano sterowane komputerowo synergiczne źródło zasilające TPS 2700 CMT firmy Fronius. W celu dobrania optymalnych warunków napawania skorzystano, we wstępnej fazie badań, z funkcji automatycznego doboru parametrów dostępnych

dr inż. Paweł Kołodziejczak, dr inż. Paweł Cegielski, prof. dr hab. inż. Andrzej Kolasa - Zakład Inżynierii Spajania Politechniki Warszawskiej. 
w urządzeniach cyfrowych serii TPS. Jest to uzasadnione z uwagi na wysoką skuteczność i powtarzalność nastaw tego typu źródeł, a także brak w dostępnych źródłach literaturowych parametrów dla takich metod jak CMT. Dla wybranej odmiany spawania (MIG CMT), gazu osłonowego (argon z wydatkiem 11-12 I/min), rodzaju materiału łączonego (wobec braku programu synergicznego dla badanego stopu magnezu, z powodzeniem zastosowano tryb przeznaczony do spawania stopu aluminium AlMg5) oraz średnicy drutu elektrodowego (wykorzystano drut elektrodowy wykonany ze stopu magnezu AZ31 o średnicy 1,2 mm), pozostałe parametry, takie jak natężenie prądu, napięcie łuku czy prędkość podawania drutu sterownik synergiczny urządzenia dobiera automatycznie na podstawie zmian jednego z nich (w tym także grubości łączonych blach).

Tablica I. Skład chemiczny stopu AZ31

Table I. Chemical composition of AZ31 alloy

\begin{tabular}{|c|c|c|c|}
\hline $\begin{array}{c}\text { Oznaczenie } \\
\text { stopu }\end{array}$ & \multicolumn{3}{|c|}{ Dodatki stopowe (\% wag.) } \\
\hline- & $\mathrm{Al}$ & $\mathrm{Mn}$ & $\mathrm{Zn}$ \\
\hline AZ31 & 3 & 0,17 & 1 \\
\hline
\end{tabular}

W celu zachowania możliwie największej obiektywności i powtarzalności wyników, wykorzystano spawalnicze stanowisko zrobotyzowane z cyfrową komunikacją robot - spawalnicze źródło zasilające. W skład systemu weszły następujące, główne elementy (rys. 1):

- robot przemysłowy IRp-6 ze zmodernizowanym układem sterowania, w tym z wewnętrznym protokołem spawalniczym [1],

- pozycjoner spawalniczy (zewnętrzna oś robota) z laboratoryjnym oprzyrządowaniem montażowym,

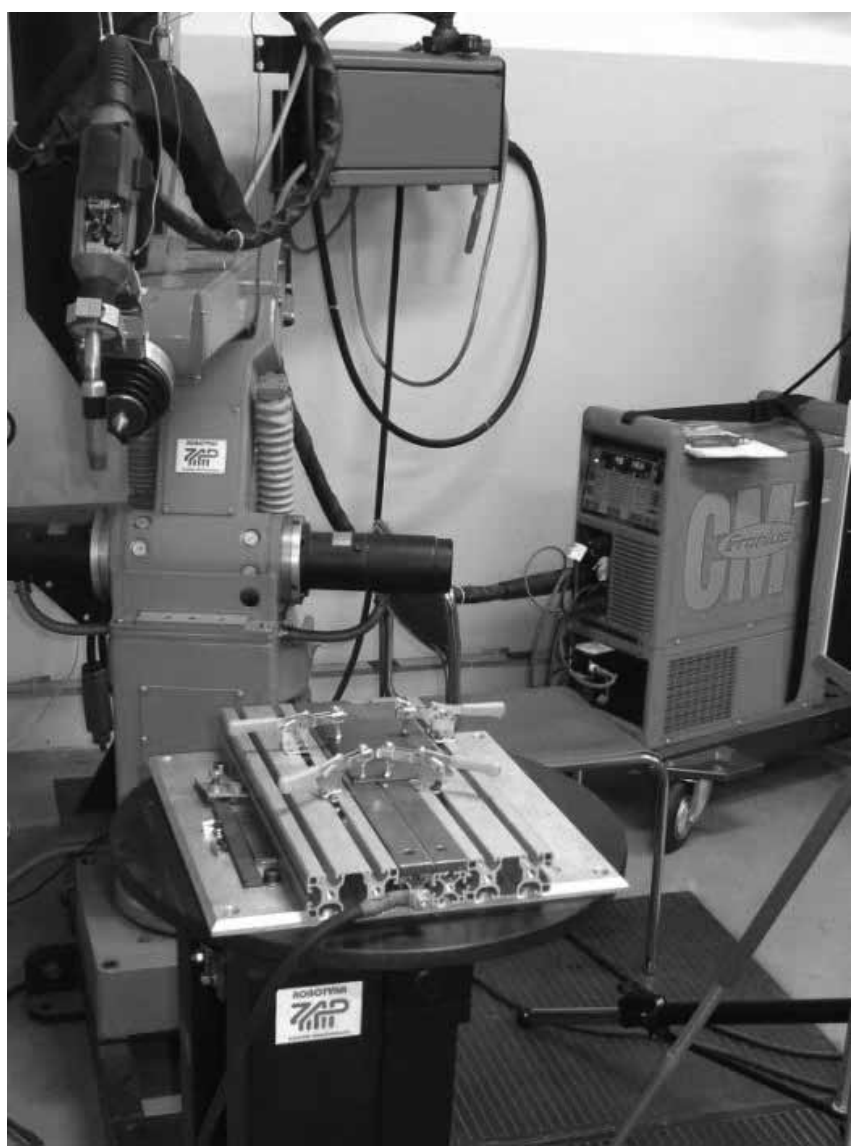

Rys. 1. Widok ogólny stanowiska laboratoryjnego z robotem IRp-6, pozycjonerem i źródłem

Fig. 1. The overall view of welding set-up used in experiment
- interfejs cyfrowy ROB 3000 (Fronius) do sterowania spawalniczym źródłem energii,

- źródło zasilające TPS 2700 CMT (Fronius).

Ujawnione podczas wstępnych badań trudności z uzyskaniem poprawnego wtopienia i kształtu złącza we wstępnej i końcowej fazie spawania skłoniły do zastosowania funkcji specjalnych źródła TPS, dostępnych przy komunikacji z robotem za pośrednictwem interfejsu cyfrowego, a wspomagających synchronizację łuku spawalniczego z ruchem roboczym maszyny $[2,3]$. Schemat możliwych modyfikacji cyklu spawania i omówienie poszczególnych funkcji przedstawiono na rysunku 2, gdzie:

- START i STOP - moment włączenia wyłączenia łuku poprzez WY $[6]=1 / 0$,

- sektor 1 - gaz osłonowy przed spawaniem,

- sektor 2 - prąd w początkowej fazie spawania (I-S [\%], t-S [s]),

- sektor 3 - dynamika przejścia pomiędzy poziomami prądu (slope [s]),

- sektor 4 - zadany, podstawowy prąd spawania (Is [A]),

- sektor 5 - prąd w końcowej fazie spawania (I-E [\%], t-E [s]),

- sektor 6 - gaz po spawaniu. Synchronizacja ruchu roboczego ze zmodyfikowaną pracą źródła zaprogramowana została w robocie IRp-6.

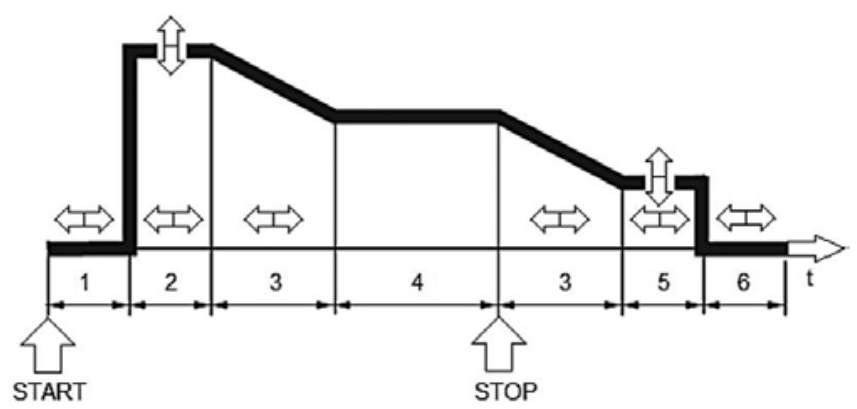

Rys. 2. Programowany w źródle spawalniczym cykl spawania MIG CMT z zaznaczonymi kierunkami regulacji

Fig. 2. The programmable MIG CMT welding current cycle. Arrows show the possibility of regulation

Ostatecznie, w układzie sterującym robot zaprogramowano następujący, nadrzędy cykl roboczy spawania, wykorzystujący cykl zaprogramowany w samym źródle (przedstawionym na rys. 2):

- WY [6] = 1 - START spawania (strzałka START na rys. 2)

- "Czekaj na WE [2] = 1" - czekanie na sygnał z czujnika źródła, potwierdzający zajarzenie łuku,

- Alternatywnie do punktu 2 "Czekaj na WE [11] = 1" - czekanie na sygnał z czujnika kontaktronowego potwierdzającego pojawienie się prądu w obwodzie spawania,

- "CZEKAJ CZAS 0,2 - 0,5 s" - opcjonalnie, spawanie w bezruchu poprzedzające ruch roboczy; w takim wypadku sektory 2 i 3 cyklu programowanego w źródle (rys. 2) mogły być realizowane (w całości lub częściowo) przed rozpoczęciem ruchu roboczego,

- „Poz LIN..." - ruch roboczy robota wzdłuż złącza (prędkość spawania programowano jako \% prędkości odniesienia - tu $500 \mathrm{~mm} / \mathrm{s}$ )

- WY [6] = 0 - STOP spawania (strzałka STOP na rys. 2)

Program badań zakładał wykonanie szeregu spoin przy różnych parametrach procesu, obejmujących zmiany parametrów podstawowych (prądu spawania $I_{s}$, napięcia łuku $U_{\mathrm{t}}$, prędkości podawania drutu elektrodowego $V_{d r}$, prędkości spawania $V_{\text {sp }}$ ) oraz specjalnych, związanych z cyklem przedstawionym na rys. 2. W tablicy II zestawiono szczegółowe parametry spawania odmianą MIG CMT, obrazujące przyjęte kierunki zmian. Spawano w pozycji podolnej. Kąty pracy i posuwu elektrody $90^{\circ}$. Wolny wysuw drutu $I_{w} 15,6 \mathrm{~mm}$ (próby $1 \div 4$ ) i 11,2 mm (pozostałe). W tablicy wyróżniono próby szerzej omówione w dalszej części artykułu. 
Tablica I. Parametry prób dobrane na podstawie programu synergicznego źródła TPS 2700 CMT (Fronius)

Table I. Welding parameters selected from the synergic TPS 2700 CMT power source programme

\begin{tabular}{|c|c|c|c|c|c|c|c|c|c|c|c|c|}
\hline \multirow{3}{*}{ Próba } & \multirow{2}{*}{$\begin{array}{l}\text { Nastawa } \\
\text { grubości } \\
\quad \neq\end{array}$} & \multirow[b]{2}{*}{ Szczelina } & \multicolumn{3}{|c|}{ Parametry źródła } & \multicolumn{2}{|c|}{ Robot } & \multicolumn{5}{|c|}{ Funkcje początkowe i końcowe cyklu (rys. 2) } \\
\hline & & & $I_{s}$ & $\mathrm{U}_{\mathrm{t}}$ & $V_{d r}$ & $V_{s p}$ & $\begin{array}{c}\text { spaw. } \\
\text { w miejscu }\end{array}$ & I-S & $\mathrm{t}-\mathrm{S}$ & I-E & $t-E$ & slope \\
\hline & {$[\mathrm{mm}]$} & {$[\mathrm{mm}]$} & [A] & {$[\mathrm{V}]$} & {$[\mathrm{m} / \mathrm{min}]$} & {$[\mathrm{mm} / \mathrm{s}]$} & [s] & [\%] & [s] & [\%] & [s] & [s] \\
\hline 1 & \multirow{6}{*}{1,6} & - & \multirow{6}{*}{85,0} & \multirow{6}{*}{12,9} & \multirow{6}{*}{5,6} & \multirow{4}{*}{20,0} & \multirow{9}{*}{0} & & & & & \\
\hline 2 & & 1,0 & & & & & & & & & & \\
\hline 3 & & \multirow{5}{*}{0} & & & & & & \multirow{11}{*}{140} & \multirow{3}{*}{0,1} & \multirow{15}{*}{\multicolumn{2}{|c|}{0}} & \multirow{6}{*}{0,1} \\
\hline 4 & & & & & & & & & & & & \\
\hline 5 & & & & & & \multirow{5}{*}{15,0} & & & & & & \\
\hline 6 & & & & & & & & & \multirow{7}{*}{1,0} & & & \\
\hline $7^{1}$ & 2,0 & & 80,0 & 15,0 & 3,8 & & & & & & & \\
\hline 8 & \multirow{10}{*}{1,6} & \multirow{4}{*}{$1,0^{2}$} & \multirow{10}{*}{85,0} & \multirow{10}{*}{12,9} & \multirow{10}{*}{5,6} & & & & & & & \\
\hline 9 & & & & & & & & & & & & \\
\hline 10 & & & & & & \multirow[b]{2}{*}{16,5} & \multirow{6}{*}{0,3} & & & & & \\
\hline 11 & & & & & & & & & & & & 0,7 \\
\hline 12 & & \multirow{5}{*}{$0,5^{2}$} & & & & \multirow{8}{*}{15,0} & & & & & & \\
\hline 13 & & & & & & & & & & & & \\
\hline 14 & & & & & & & & 0 & 0 & & & 0 \\
\hline $15^{3}$ & & & & & & & & & & & & \\
\hline $16^{3}$ & & & & & & & & 160 & & & & \\
\hline 17 & & 0 & & & & & 0,0 & & 1,0 & & & 0,7 \\
\hline 70 & 80 & $0,5^{2}$ & 020 & 120 & 60 & & 0 & 60 & & 50 & 05 & \\
\hline 18 & 2,0 & napoina & 93,0 & 13,3 & 0,0 & & 0 & 60 & & 50 & 0,5 & \\
\hline 19 & & & & apoiny & zy obniżo & ych param & etrach (niekl & asyfiko & & & & \\
\hline 20 & 2,0 & & 93,0 & 13,3 & 6,0 & & & & & & & \\
\hline 21 & 1,0 & napina & 65,0 & 12,5 & 4,0 & & & & & & & \\
\hline 22 & & & & & & & & & & & & \\
\hline $23^{4}$ & & $0,5^{2}$ & & & & & 0 & & & 0 & & \\
\hline $24^{5}$ & 1,6 & $0,8^{2}$ & 85,0 & 12,9 & 5,6 & & & & & & & \\
\hline $25^{5}$ & & $10-05^{2}$ & & & & $10,0-15,0$ & & & & & & \\
\hline $26^{5}$ & & $1,0-0,0$ & & & & & & & & & & \\
\hline
\end{tabular}

\section{Wstępne wyniki spawania}

Złącza uzyskiwane podczas pierwszych prób odznaczały się szeregiem wad i niezgodności, zarówno w fazie początkowej (braki wtopienia) jak i końcowej (przepalenia, kratery w miejscu końcowego jeziorka). Podczas próby nr 8 (rys. 3) włączono funkcję hot start (prąd I-S / t-S w początkowej fazie spawania $140 \%$ w stosunku do prądu zadanego przez $1 \mathrm{~s})$, dynamika przejścia pomiędzy poziomami prądu slope ustawiona na poziomie $0,1 \mathrm{~s}$, a funkcja zamykania krateru (prąd w końcowej fazie spawania I-E / t-E) została wyłączona. Start ruchu roboczego następował od razu po potwierdzeniu zajarzenia łuku. Złącze wykonano ze szczeliną $1 \mathrm{~mm}$. W początkowej fazie spoina ma nadmierny nadlew i brak jest wtopienia. W dalszej części pojawia się przewężenie spoiny oraz jej nieciągłość. Dodatkowo, podczas spawania zaobserwowano $w$ tym miejscu niestabilne zachowanie łuku spawalniczego. Okazało się, że jest to miejsce przejścia prądu od wartości początkowej (I-S 140\% przez $1 \mathrm{~s}$ z prędkością $15 \mathrm{~mm} / \mathrm{s}$ ) do wartości prądu bazowego. Podejrzenie padło na zbyt krótki czas przejścia pomiędzy poziomami prądu slope. Zmiana prądu ze $140 \%$ do poziomu podstawowego w czasie 0,1 s skutkowało niemal chwilowym zatrzymaniem podawania drutu. To z kolei zaburzało jarzenie się łuku i uniemożliwiało wykonanie poprawnej spoiny. Wobec nie ustawienia obniżonej wartości prądu końcowego (I-E, $t-E)$, na końcu spoiny powstało przepalenie.

Zmiana czasu przejścia pomiędzy poziomami (slope) z 0,1 na 0,7 s spowodowała płynne przejście od wartości początkowej (podwyższonej) do podstawowej i znacznie lepszy obraz lica spoiny (próba nr 9, rys. 4). Niestety, nadal w początkowej fazie brak jest przetopu (rys. 5). Bez zmian pozostało również końcowe przepalenie. 


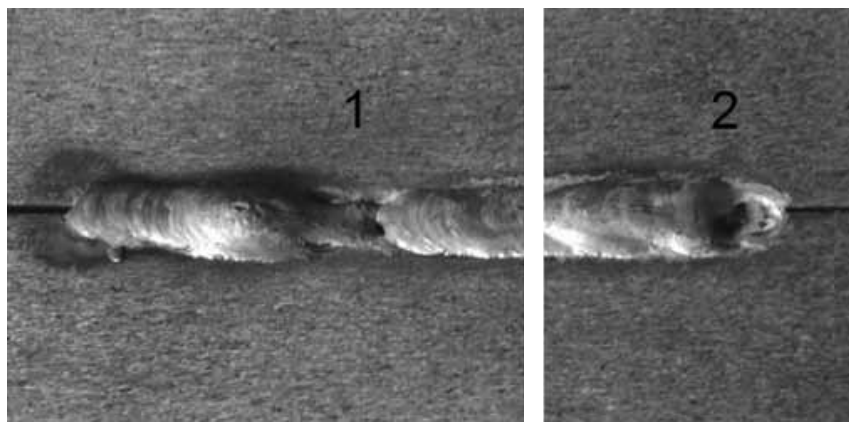

Rys. 3. Próba nr 8. Lico spoiny w fazie początkowej i końcowej Fig. 3. Sample No. 8. Weld bead 1- beginning of a weld, 2- end of a weld

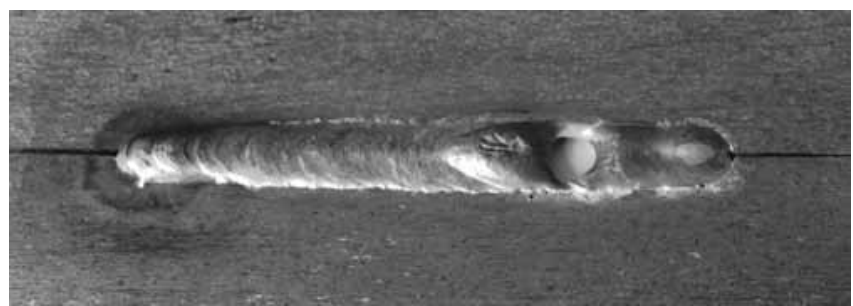

Rys. 4. Próba $\mathrm{nr} 9$. Lico spoiny

Fig. 4. Sample No. 9. Weld bead

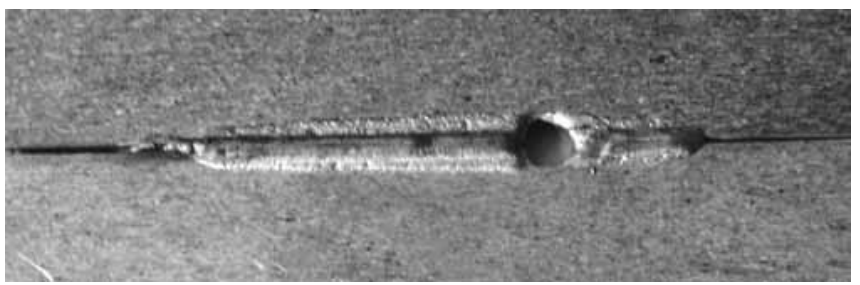

Rys. 5. Próba nr 9. Grań spoiny

Fig. 5. Sample No. 9. Weld root

W celu uzyskania poprawnego wtopienia w początkowej fazie spawania dodatkowo zaprogramowano opóźnienie startu ruchu roboczego po sygnale potwierdzającym zajarzenie łuku (poprzez wejście nr 11) na 0,2 s (próba nr 10 na rys. 6). Krótkotrwałe, wstępne jarzenie się łuku w bezruchu podgrzewa materiał i zapewnia poprawne wtopienie spoiny. Przejście pomiędzy prądem początkowym a wartością podstawową nadal jest płynne i estetyczne. Przepalenie pojawiło się nieco wcześniej, najprawdopodobniej wskutek zwiększonej ilości ciepła dostarczonego w początkowej fazie spawania.

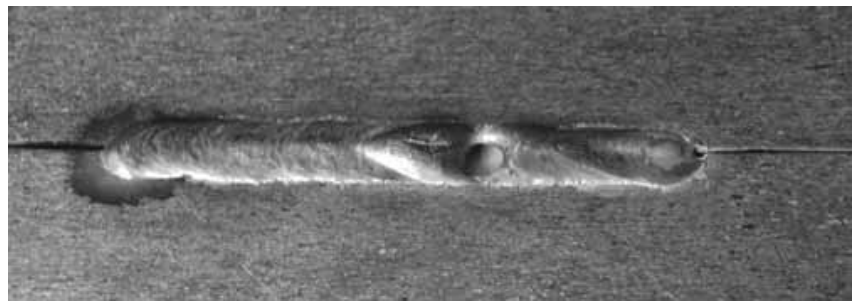

Rys. 6. Próba nr 10. Lico spoiny

Fig. 6. Sample No. 10. Weld bead

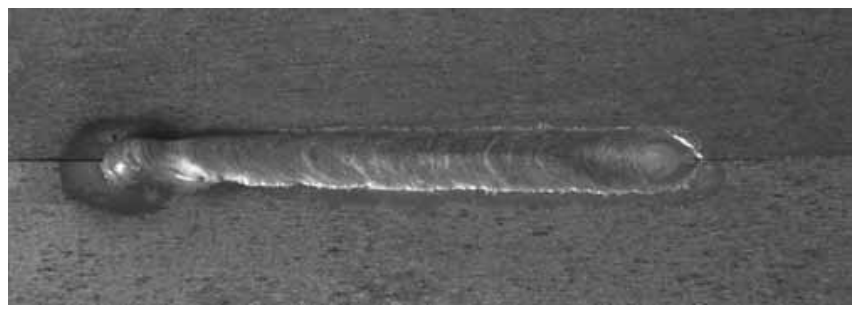

Rys. 7. Próba $\mathrm{nr}$ 12. Lico spoiny

Fig. 7. Sample No. 12. Weld bead
Wramach kolejnych prób zmniejszono szczelinę do 0,5 $\mathrm{mm}$ (próba $\mathrm{nr} 12$ na rys. 7 i 8). Wyeliminowało to problem przepaleń, a zakończenie spoiny odznaczało się dobrym wyglądem, zarówno od strony lica (jednak z wydłużonym, końcowym kraterem), jak i grani. Ponownie pojawił jednak się problem z wtopieniem w początkowej fazie spoiny.

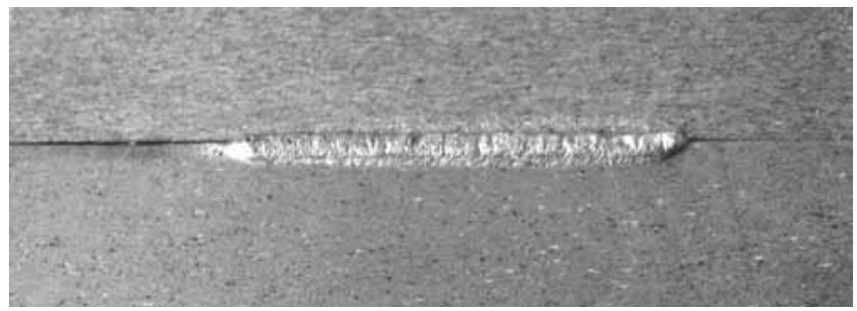

Rys. 8. Próba nr 12. Grań spoiny

Fig. 8. Sample No. 12. Weld root

W ramach kolejnych prób m.in. dodatkowo włączono funkcję "zamykania krateru", polegającą na zadaniu obniżonego poziomu prądu końcowego I-E (ustawiono 50\%) w zadanym czasie (ustawiono t-E na 0,5 s). Uzyskana napoina (próba nr 18) ujawniła kolejny problem - po sygnale STOP spawania (rys. 2), a więc po zatrzymaniu ruchu robota, następowała trwająca 0,7 s faza przejścia pomiędzy poziomami (slope) oraz faza prądu końcowego (50\% przez 0,5 s). Spowodowało to przepalenie napoiny.

Na podstawie badań wizualnych do dalszych badań metalograficznych wytypowano próby nr 10 (rys. 6) i 12 (rys. 7).

W celu przygotowania próbek do badań mikroskopowych otrzymane złącza przecięto mechanicznie prostopadle do osi spoiny w dwóch miejscach: około $5 \mathrm{~mm}$ od początku spoiny (w obszarze zajarzania łuku) i w połowie złącza (w obszarze stabilnego procesu). Tak pobrane próbki wyszlifowano i wypolerowano, następnie trawino nitalem przez około $30 \mathrm{~s}$. Uzyskane zgłady metalograficzne obserwowano na mikroskopie optycznym z cyfrową rejestracją obrazu (rys. 9 i 10).

Przeprowadzona analiza makroskopowa otrzymanych połączeń pozwala stwierdzić, że otrzymane złącza wolne są od pęknięć, zaś strefa wpływu ciepła ma podobną wielkość dla wszystkich dla poszczególnych próbek, co wynika z wysokiego współczynnika przewodzenia ciepła magnezu. Otrzymane różnice między kształtem spoiny w na początku procesu spawania i w trakcie jego trwania potwierdziły występowanie pewnych niestabilności w fazie zajarzania
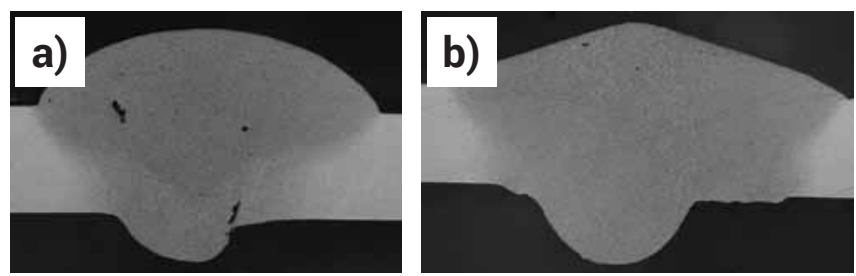

Rys. 9. Próbka nr 10 - makrostruktura spoiny x25, a) początek spoiny, b) środek spoiny

Fig. 9. Sample No. 10 - macrostructure of the weld x25 a) beginning of a weld, b) a weld

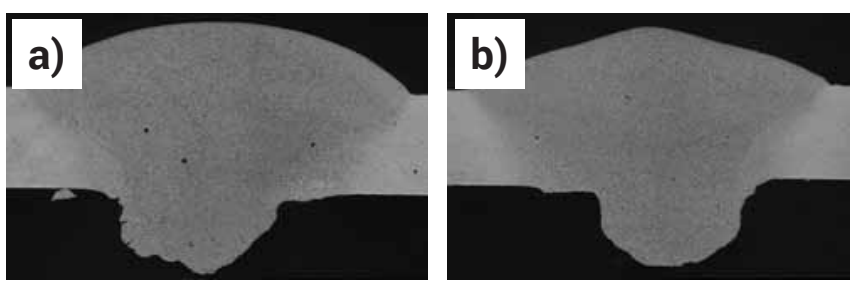

Rys. 10. Próbka nr 12 - makrostruktura spoiny x25, a) początek spoiny, b) środek spoiny

Fig. 10. Sample No. 12 - macrostructure of the weld x25 a) beginning of a weld, b) a weld 
łuku. Mogą one być spowodowane brakiem wstępnego podgrzewania próbek, bądź niewydolnością układu regulacyjne- go urządzenia spawającego. Niestabilności te objawiają się zaburzeniami kształtu w obszarze grani.

\section{Podsumowanie}

Wykonane badania potwierdziły dane literaturowe, że magnez jest materiałem trudno spawalnym, wrażliwym nawet na minimalną zmianę parametrów procesu spawania. Nawet zastosowanie zaawansowanych funkcji urządzenia nie pozwoliło w trakcie tych badań na wyeliminowanie niekorzystnego kształtu spoiny w początkowej fazie spawania. Ważna rolę na jakość uzyskanych złączy odgrywa także położenie względem siebie krawędzi łączonych materiałów, zmiana szczeliny o 0,5 mm powodowała przepalenie, bądź brak przetopu.

Przedstawione w pracy badania mają charakter wstępny i wymagają dalszego ich prowadzenia w celu wyeliminowania niekorzystnych efektów zmiany geometrii spoiny w różnych fazach procesu spawania.

\section{Literatura}

[1] Kolasa A., Cegielski P., Sarnowski T. „Krajowe stanowisko zrobotyzowanego spawania metodą MIG/MAG." Przegląd Spawalnictwa 12/1998, str. 3-6

[2] Cegielski P. „Synchronizacja spawania MIG/MAG z ruchem roboczym" Przegląd Spawalnictwa 2/2015, str. 55-57

[3] Trans Synergic, Trans Puls Synergic 2700/4000/5000. Instrukcja obsługi. Fronius

[4] Kołodziejczak P., Kolasa A., Skrzyniecki K., Cegielski P. „Spawanie stopu magnezu z grupy AM metodą MIG", Przegląd Spawalnictwa $11 / 2013$, str. 36-40

[5] Mordike B.L., Ebert T.: Magnesium. Properties - applications - potential. Material Science and Engineering, A302, 2001, pp. 37-45.
[6] L. Tuz, P. Kołodziejczak, A. Kolasa, Struktura złączy stopów AZ91 i AM-Lite wykonanych metodą TIG, Przegląd Spawalnictwa 12/2010, s. $37-41$

[7] P. Kołodziejczak, W Kalita: Properties of $\mathrm{CO} 2$ laser-welded butt joints of dissimilar magnesium alloys, Jurnal of Materials Pocessing Technology, 01/ 2009, 1122-1128

[8] L. Kwiatkowski, M. Grobelny, W. Kalita, P. Kołodziejczak, Corrosion properties of the butt-welded joints of laser welded Mg alloys, Inżynieria Powierzchni 2A-2005, s. 191-197.

[9] L. Tuz, P. Kołodziejczak, A. Kolasa, Zgrzewanie tarciowe metodą FSW stopów magnezu AZ91 i AM-Lite, Przegląd Spawalnictwa 11/2009, s. 41-44 